\title{
RECOMENDAÇÕES TÉCNICAS À PREVENÇÃO DE FENÔMENOS PATOLÓGICOS EM \\ PISOS DE CONCRETO ARMADO: AMBIENTE INDUSTRIAL TÊXTIL SOB AÇÃO DE \\ SOLUÇÕES ÁCIDAS
}

\author{
TECHNICAL RECOMMENDATIONS FOR THE PREVENTION OF PATHOLOGICAL \\ PHENOMENA IN ARMED CONCRETE FLOORS: INDUSTRIAL ENVIRONMENT TEXTILE \\ UNDER ACTION OF ACID SOLUTIONS
}

Maicon Anderson de Souza ${ }^{1}$

Tiago Dell Agnolo ${ }^{2}$

\section{RESUMO}

As estruturas de concreto armado estão presentes na construção brasileira em grande escala e cada vez mais os técnicos e responsáveis da área deparam-se com problemas e reparos relacionados a fatores ocasionados por solicitações intensas, ambientes agressivos, entre outros. No presente trabalho realizou-se um estudo da estrutura de um piso industrial de concreto armado de uma tinturaria de Brusque (SC), com o objetivo de identificar quais os agentes agressivos que atuam no processo de degradação do piso em concreto armado de uma indústria têxtil. A metodologia teve abordagem qualitativa e quantitativa; quanto aos procedimentos técnicos se caracterizou como bibliográfica aliada ao estudo de campo. Os resultados mostraram que mesmo com baixas taxas de porcentagem de áreas atingidas por ataque de soluções ácidas, os pisos industriais necessitam ser revestidos apropriadamente, a fim de evitar as manifestações patológicas oriundas de ambientes agressivos. Ainda mostraram que as patologias identificadas, foram principalmente, em áreas molhadas, ou seja, ao lado de cada máquina de tingimento no piso da tinturaria, ocasionada por ataques de corantes diluídos em água que formam soluções ácidas, uma vez que a máquina do processo de tingimento faz uso

\footnotetext{
${ }^{1}$ Graduado em Engenharia Civil, pela Universidade Alto Vale do Itajaí - UNIVALI. Email:

eng_maicon@hotmail.com.

${ }^{2}$ Graduado em Engenharia Civil, pela Universidade Alto Vale do Itajaí - UNIVALI. Email: tiagodellagnolo@gmail.com.
} 
desses em suas composições para realizar o tingimento. Os ácidos são altamente agressivos às estruturas de concreto armado, principalmente, quando em contato direto com o concreto, pois desintegra a pasta de cimento e expõe os agregados, tornando-o com o passar do tempo ainda mais suscetível à degradação. Conclui-se que a lixiviação é responsável por degradar a capa do concreto pela infiltração de soluções ácidas e de água sobre os poros do concreto, reduzindo sua resistência mecânica.

Palavras-Chave: Concreto Armado. Patologia. Piso Industrial Tinturaria.

\section{ABSTRACT}

Reinforced concrete structures are present in Brazilian construction on a large scale and more and more technicians and managers in the area are faced with problems and repairs related to factors caused by intense requests, aggressive environments, among others. In the present work, a study of the structure of an industrial concrete floor of a Brusque dyeing plant was carried out in order to identify the aggressive agents that act in the process of degradation of the reinforced concrete floor of a textile industry. The methodology had a qualitative and quantitative approach; technical procedures was characterized as a bibliography allied to the field study. The results showed that even with low percentages of areas hit by acid solutions, industrial floors need to be properly coated in order to avoid pathological manifestations from aggressive environments. They also showed that the identified pathologies were mainly in wet areas, that is, next to each dyeing machine on the dyeing floor, caused by attacks of dyes diluted in water that form acidic solutions, since the process machine dyeing makes use of these in their compositions to accomplish the dyeing. Acids are highly aggressive to reinforced concrete structures, especially when in direct contact with the concrete, as it disintegrates the cement paste and exposes the aggregates, making it over time even more susceptible to degradation. It is concluded that the leaching is responsible for degrading the concrete cover by the infiltration of acidic solutions and water over the pores of the concrete, reducing its mechanical resistance.

Keywords: Armed Concrete. Pathology. Industrial Dyeing Floor.

\section{INTRODUÇÃO}

As estruturas de concreto estão cada vez mais presentes em ambientes agressivos, por isso a ABNT (NBR 6118, 2014) - Projeto de estruturas de concreto Procedimento em seu conteúdo aborda itens sobre agressividade de ambientes e suas classes. A classe de agressividade é definida conforme o tipo de ambiente em 
que será instituída a edificação, serve para dar garantia e qualidade à estrutura, além de estar diretamente ligada às ações físicas e químicas que agirão sobre as estruturas de concreto, visto que a definição da classe ambiental deve ser realizada em fase projetual, pois influenciará em vários fatores característicos.

O Brasil adota o uso de estruturas de concreto armado devido aos seus materiais constituintes estarem largamente disponíveis no mercado, além de ser um sistema que apresenta baixo custo, boa durabilidade, resistência à compressão, bem como ao fogo e água. O aço aliado ao concreto auxilia-o em suas características (ductilidade e excelente resistência à tração e à compressão), o que permite construir elementos com as mais variadas formas e volumes, com relativa rapidez e facilidade, para os mais variados tipos de obra (BASTOS, 2014).

No caso das estruturas de concreto armado, iniciou-se, a partir da década de 70, uma crescente preocupação com sua deterioração e durabilidade (MEDEIROS, 2008). De acordo com Gaier (2005), a demanda por técnicas e materiais de reparo crescente em nossa sociedade, aliada à idade de nossas construções, faz que os fenômenos patológicos cresçam na mesma proporção.

Infelizmente, nenhum sistema estrutural é eterno, mesmo com uma manutenção periódica. Tais fatores devem-se à ação dos agentes ambientais sobre seus componentes, agentes esses descritos na ABNT (NBR 6118, 2014), assim sendo se faz necessário o cumprimento desses parâmetros de modo a minimizar ou tentar evitar as manifestações patológicas, de maneira especial, em pisos de concreto armado.

É comum o uso de pisos de concreto em áreas industriais, uma vez que eles estão associados à sua capacidade de resistência, ou seja, devem ser projetados e executados de acordo com suas especificações, de modo a resistir às cargas atuantes, abrasão, degradação, evitando assim, que a estrutura perca sua funcionalidade. Os pisos de concreto armado utilizados nas indústrias merecem destaque, já que são os elementos que têm a finalidade de resistir e distribuir ao subleito esforços verticais provenientes dos carregamentos, bem como operam em atividades de movimentação de cargas e de equipamentos (ANACLETO, 2014).

Para Cruz (2015), a correta execução dos pisos industriais de concreto é fundamental para garantir seu desempenho, eliminando ou mitigando os efeitos deletérios que possam ocorrer desde o projeto até sua utilização, evitando a suposta 
degradação das estruturas.

Existem diversos fatores que podem influenciar na degradação das estruturas de concreto, por exemplo, gases, vapores e líquidos, que adentram pelos poros e fissuras do concreto, presença de umidade como chuvas, bem como as próprias características dos materiais que constituem o concreto (NEPOMUCENO, 2005).

Nessa direção, Anacleto (2014) afirma que quando as manifestações patológicas ocorrem nos pisos industriais de concreto, não advêm de maneira isolada ou somente de maneira a prejudicar a estética dele, acarretam também a perda de funcionalidade, uma vez que as mais variadas falhas observadas tendem a comprometer a operação de cargas, e a resistência estrutural desse elemento, dando origem às patologias.

Na visão de Santos (2012), as patologias das estruturas de concreto armado podem surgir das etapas de concepção e elaboração do projeto, execução, uso e manutenção, como também por outros fatores como: teor de álcalis ${ }^{3}$ presentes no cimento, classe de agressividade do ambiente, interferindo dessa forma no desempenho, durabilidade e vida útil da estrutura.

Nesse aspecto, Ferreira, Lima e Meira (2013) asseveram que os agentes agressivos atuam sobre os produtos constituintes do Cimento Portland, pois ele não se apresenta resistente quando deparado em ambientes ácidos ou em contato com soluções ácidas, ficando suscetível a diversos motivos, tais como: permeabilidade, a concentração e tipo de ácido.

Nessa perspectiva de estudo, observa-se a importância de se efetuar a proteção das superfícies expostas ao ambiente agressivo, seja por meio de hidrófugos ou outros sistemas, a fim de minimizar a infiltração de água, uma vez que a lixiviação causada pela ação de águas puras, carbônicas agressivas e ácidas dissolvem os compostos hidratados da pasta de cimento, (ABNT NBR 6118, 2014).

A indústria tem um papel fundamental no crescimento na economia de um país, pois abre as portas do comércio e, assim, gera emprego à população, gerando aos seus operários uma renda para sobreviver e possuírem uma qualidade de vida.

3 Teor de álcalis: contém presença de sódio e potássio, o cimento é a principal fonte de álcalis. Fonte: Ubaldo e Moraes (2014). 
Dessa forma, a indústria têxtil fica responsável por transformar a matéria-prima, por meio de processos em produtos que necessitamos consumir e fazer uso, seja roupa ou artigos de cama, mesa e banho.

Nesse cenário, o estudo de manifestações patológicas é um dos vários campos de estudo da construção civil, pois faz que diversos profissionais das áreas tanto engenheiros quanto arquitetos mantenham um controle de qualidade, aumentando assim, a vida útil da estrutura e evitando que ela venha a se comprometer. Esse controle pode ser realizado, por exemplo, por meio de observações ou até mesmo manutenções periódicas.

O local a ser realizado o estudo de campo é uma tinturaria, considerado um ambiente industrial de agressividade CAA IV, ou seja, que é atacado por agentes agressivos ácidos, que provocam a deterioração do piso e expõe seus agregados. Nesse contexto, questionamos: "Quais as recomendações para mitigar ou eliminar os fenômenos patológicos oriundos de ataques ácidos em piso de uma indústria têxtil?".

\section{METODOLOGIA}

A pesquisa realizada neste trabalho tratou-se da identificação de fenômenos patológicos detectadas no piso industrial de concreto armado de uma tinturaria situada no munícipio de Brusque (SC), em especial, os originados por ataques ácidos e lixiviações.

A população é uma tinturaria do município de Brusque e a amostra seria o piso de concreto armado da mesma.

Os registros das patologias e suas análises ocorreram entre os dias 6 a 31 de março, quando foram desprendidas aproximadamente 60 horas de observações e acompanhamento dos processos realizados nos setores da empresa, sendo em seguida a realização de uma pesquisa, indicando quais as possíveis origens das manifestações patológicas e quais os métodos de tratamento que poderiam ser aplicados aos problemas.

A pesquisa a seguir tem por objetivo a identificação dos agentes agressores ao piso de concreto armado da indústria têxtil. 


\section{EMPRESA}

O piso industrial a ser estudado é referente a uma tinturaria, esta empresa é responsável por fazer o tingimento e dar acabamento final às malhas que chegam. A empresa localiza-se no município de Brusque (SC), e possui uma área total de aproximadamente $17.000 \mathrm{~m}^{2}$. Porém, o estudo realizou-se em apenas $10.000 \mathrm{~m}^{2}$ dos $17.000 \mathrm{~m}^{2}$, ou seja, onde se encontra o piso de concreto armado. Todos os setores são bem arejados, possuindo presença de uma grande quantidade de iluminação natural por intermédio de janelas na maioria dos setores e em alguns setores telha translucida, além de sua ventilação ser eficaz, os setores não possuem controle de umidade do ar. O tipo piso adotado pela empresa foi o piso de concreto simples, com armadura descontínua de retração.

A empresa está dividida por oito setores de produção, sendo estes: planejamento e controle da produção (pcp), depósito, setor de pesagem, máquinas de tingimento, lavação, calandragem, rama, por fim, expedição, conforme se mostra na Figura 25. Em todos os setores da empresa, os pisos apresentam-se com uma espessura de concreto de aproximadamente $12 \mathrm{~cm}$, fck13 30, porém a idade dos pisos varia entre os setores. Na Figura 01 é possível identificar a localização dos setores.

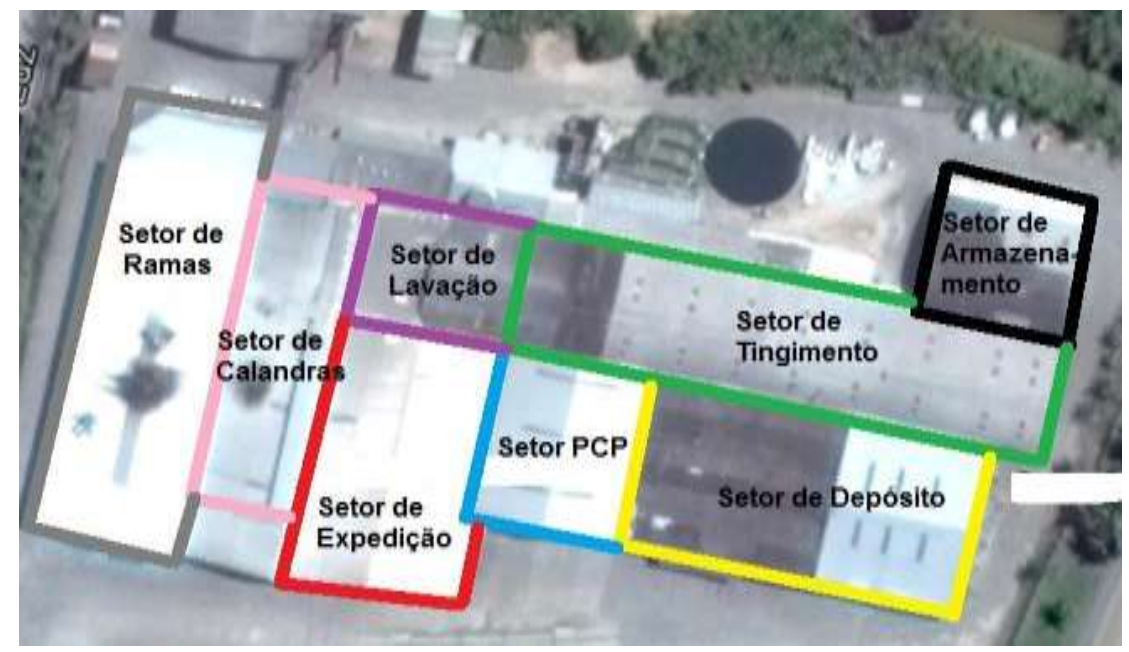

Figura 1 - Divisão de setores da empresa

Fonte: Autores, 2017. 
A seguir, são descritos alguns dos setores de produção da indústria, e identificados suas patologias quando existentes.

\section{SETOR PCP}

PCP significa Planejamento e Controle da Produção, este setor possui uma área de $1.200 \mathrm{~m}^{2}$, e o piso de seu setor possui uma idade de aproximadamente 20 anos. Esse é setor no qual os caminhões descarregam as malhas enviadas pelos clientes, a fim de ser realizado o processo de tingimento.

Nesse setor, assim que a malha chega à empresa, é feita a pesagem e a sua separação. A separação das malhas é feita pela ordem de serviço (O.S.), na qual são descritas a quantidade de malha, o tipo, qual o processo irá sofrer, definição de cor, processo de acabamento adotado, e esse lote recebe um número de identificação, conforme Figura 02. Após a ordem de serviço estabelecida, é efetuada a montagem dos lotes. Em seguida, a malha é direcionada ao setor de tingimento.

Figura 2 - Setor de Planejamento e Controle da Produção

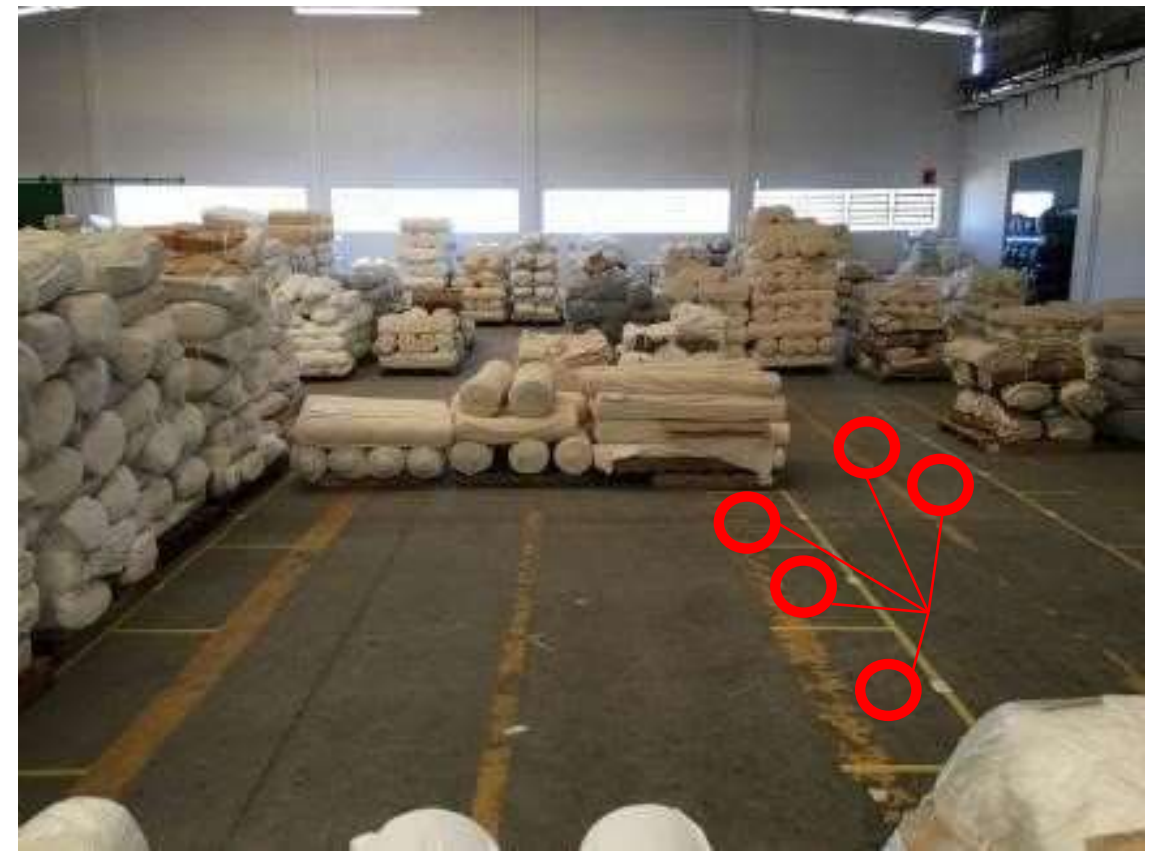

Fonte: Autores, 2017

Como pode-se observar na Figura 02, as malhas são separadas por clientes 
e identificadas sobre o piso com uma numeração, porém esse setor se apresenta seco, ou seja, não há presença de água ou produtos químicos atuantes sobre esse piso.

\section{SETOR DE ARMAZENAMENTO DE PRODUTOS QUÍMICOS}

Neste setor fica armazenado produtos químicos sólidos e líquidos os quais são utilizados diariamente pela empresa. Esse setor se encontra com uma área de aproximadamente $400 \mathrm{~m}^{2}$, sendo dividida em $200 \mathrm{~m}^{2}$ para produtos sólidos e 200 $\mathrm{m}^{2}$ para produtos líquidos.

Essa área é completamente atingida por umidade, já que o piso precisa ser lavado a cada troca de turno, uma vez que ali, também, se localiza a balança, na qual se realiza a pesagem de todos os produtos sólidos e alguns ácidos (que estão desconectados da cozinha de alimentação) utilizados nas máquinas de tingimento.

A umidade se dá pelo fato de o operador, que manuseia a balança, deixar cair sobre o piso produtos químicos utilizados no processo de tingimento, fazendo que, assim, o piso seja lavado três vezes ao dia. A idade desse piso é de apenas seis meses.

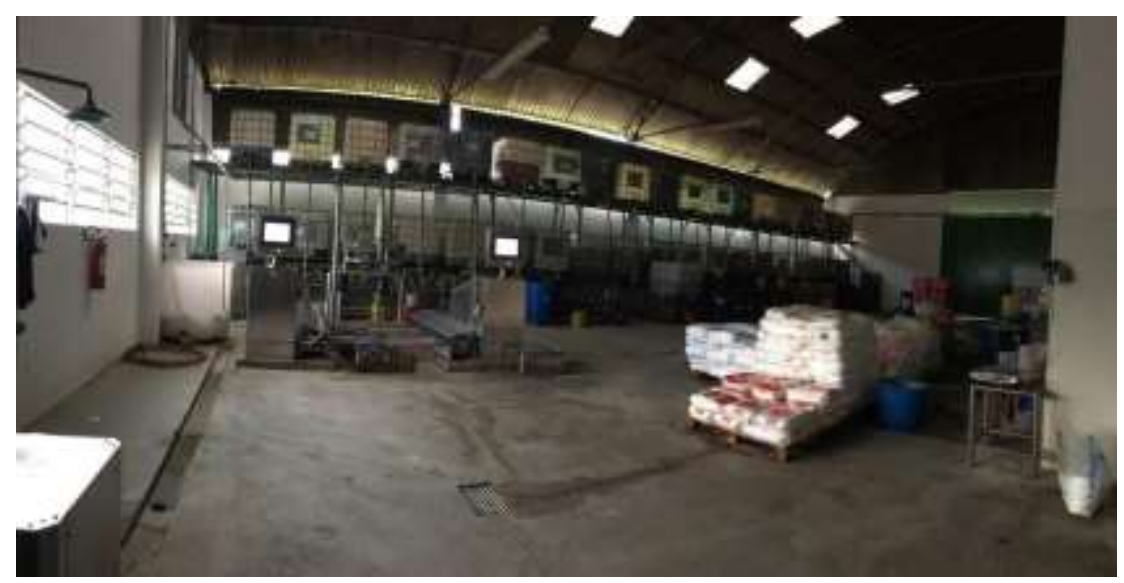

Figura 3 - Armazenamento de Produtos

Fonte: Autores, 2017.

A Figura 03 mostra o local de armazenamento e a disposição dos seus componentes, tanto químicos como líquidos. Observa-se que mesmo o piso possuindo apenas seis meses de execução já apresenta manifestações patológicas, 
as quais serão mostradas mais adiante.

Os produtos químicos sólidos (corantes de $\mathrm{pH}$ 3-6) precisam ser pesados manualmente, por isso, nesse local, conforme a Figura 04, há um determinado espaço com balança, no qual o operador manualmente e conforme a receita da ordem de serviço, determina a quantidade adequada de cada item, direcionando, em seguida, o produto já pesado e diluído em água ao lado da máquina.

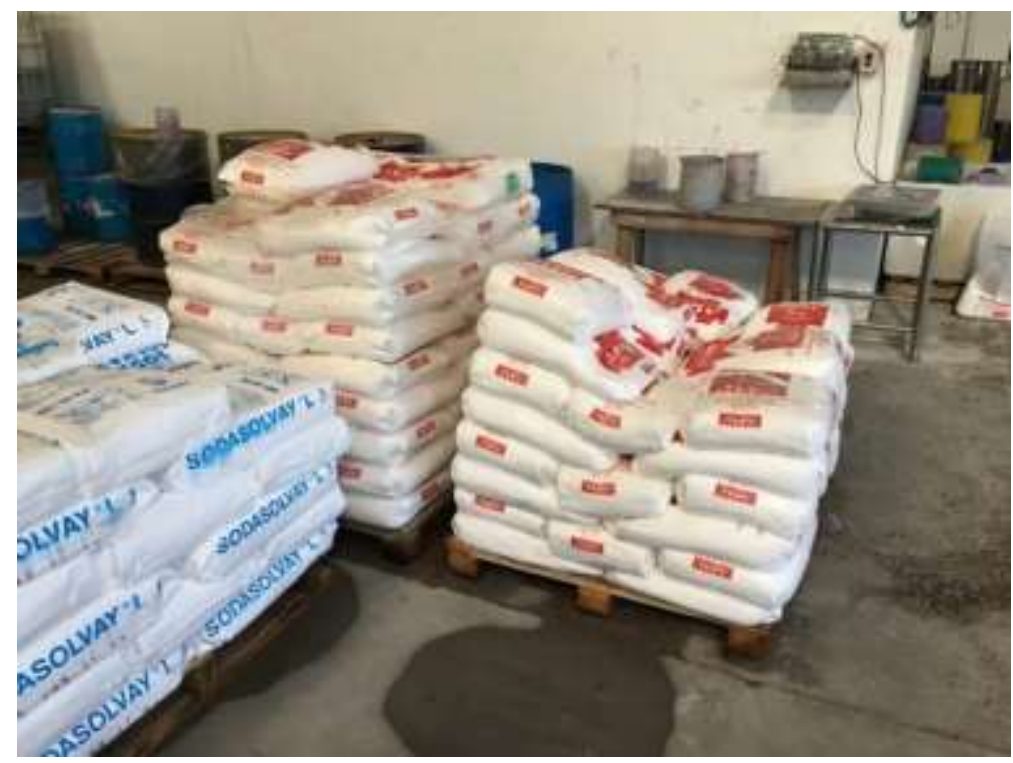

Figura 4 - Balança de Sólidos

Fonte: Autores, 2017.

Como este local é onde o operador pesa os produtos químicos sólidos, geralmente caem resíduos sobre o piso, precisando ser lavado constantemente.

Já os produtos químicos líquidos (os ácidos cujo $\mathrm{pH}$ podem variar) ao contrário dos sólidos, não precisam ser pesados, pois são enviados automaticamente pela cozinha de alimentação através de mangueiras que fazem o bombeamento, de acordo com a receita que o operador da máquina de tingimento solicitar no painel eletrônico. 


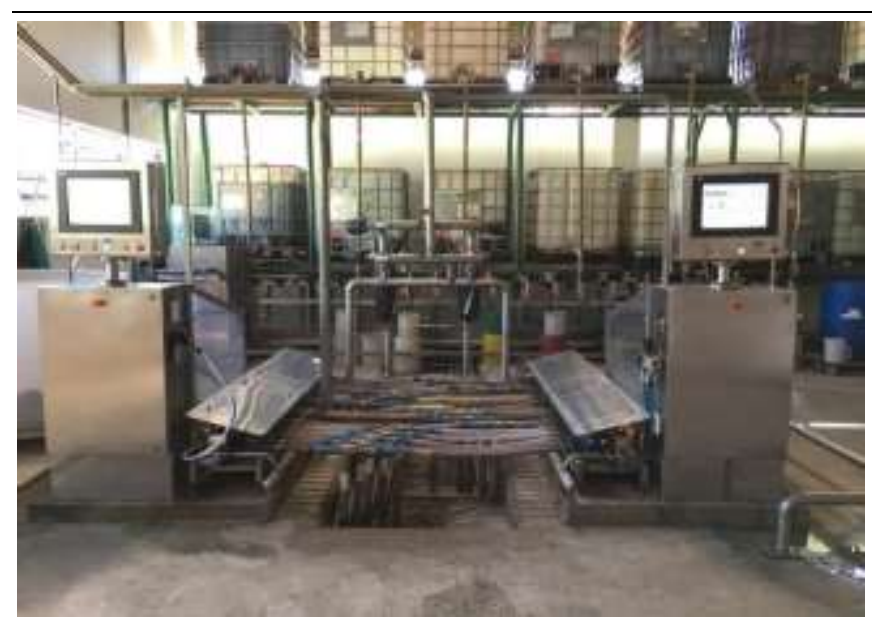

Figura 5 - Cozinha de alimentação automática Fonte: Autores, 2017.

Como se pode observar, esse setor possui diversos containers plásticos de 1000,00 I, os quais são localizados em dois patamares diferentes. O patamar superior é interligado ao inferior, servindo para reabastecer o container situado no patamar inferior, por meio de gravidade.

Os containers localizados na parte inferior do patamar são responsáveis por encaminhar os produtos químicos ácidos por meio de gravidade para a cozinha de alimentação (Figura 06).

Figura 6 - Cozinha de alimentação de máquinas

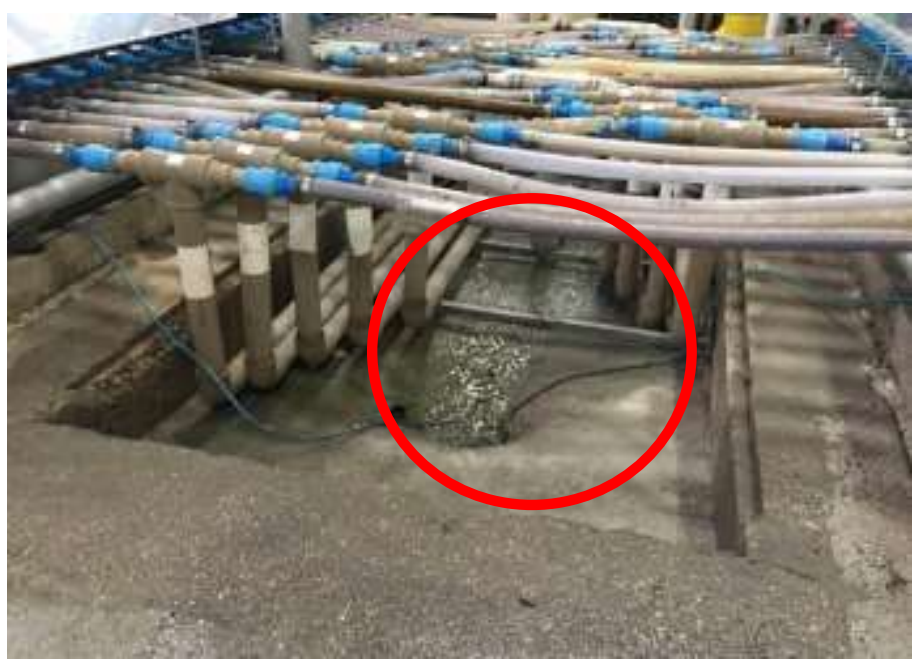

Fonte: Autores, 2017

Ignis / Caçador | v.7 | n.3 | p. 128-147 | set./dez. 2018 
Observa-se uma deterioração da pasta de cimento no seu interior, esta é ocasionada por resíduos de produtos químicos líquidos (ácidos) e água, principalmente, quando o piso é lavado porque o ácido juntamente com água escoa até a canaleta. Muitas vezes ao término do dia, a cozinha é desligada; porém, mesmo que desligada, as mangueiras apresentam um vazamento de ácidos, ocasionado a patologia.

É possível ainda observar o efeito da lixiviação. Pelo ataque dos ácidos ocorre a lixiviação, pois o concreto é agredido, tanto pelo contato da água pura (no caso a água usada para lavar o piso) como também pela entrada de gases e ácidos por seus poros, perdendo assim sua resistência e suas características cimentantes, interferindo também em sua estética, já que a pasta de cimento fica comprometida.

Assim, é possível identificar a deterioração do piso de concreto, causado, em especial, pelo contato do produto químico ácido. O contato do ácido com o concreto nesse setor ocorre quando o produto precisa ser retirado, manualmente, a fim de ser pesado, isso porque existem duas máquinas de tingimento que não estão ligadas à cozinha automatizada. Registrou-se $12 \mathrm{~m}^{2}$ de área afetada causada por produtos líquidos (ácidos) nesse setor.

\section{SETOR DE TINGIMENTO}

O piso do setor de tingimento possui uma idade de aproximadamente 8 anos e uma área total de $2.000 \mathrm{~m}^{2}$, onde estão localizadas trinta e cinco máquinas que são responsáveis por dar tingimento, ou seja, cor as malhas. As malhas que estavam no setor do pcp são diretamente encaminhadas para este setor, onde são direcionadas a diferentes tipos de máquinas, conforme o peso e cor. Nesse setor foi possível identificar a ação de três corantes que quando diluídos em água formam soluções ácidas, conhecidos comercialmente por Preto Sidercron Vsb 133\%, Vermelho Sidercron Bf 150\%, Preto Sidercron Pfr, conforme mostrado na Figura 7. 


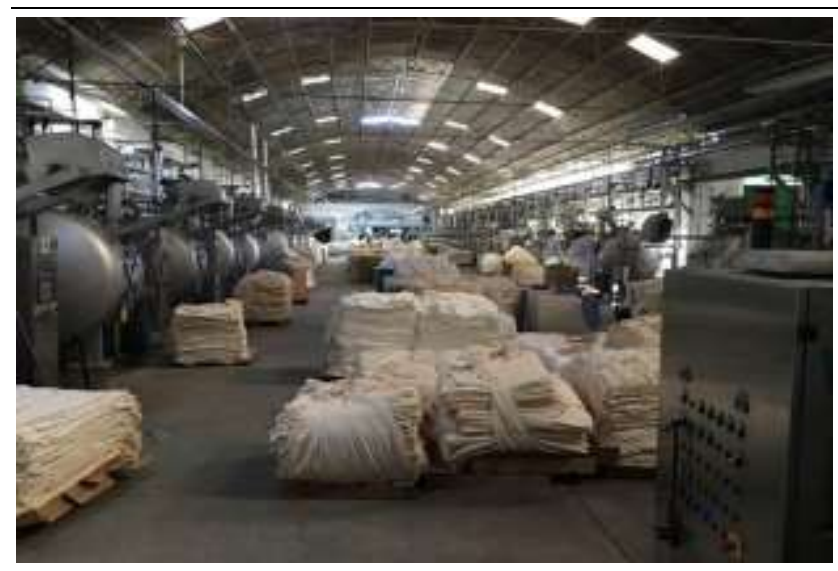

Figura 7 - Setor de Tingimento

Fonte: Autores, 2017.

Neste setor se encontram patologias ocasionadas pelo contato de corantes que quando diluídos em água formam soluções ácidas, que precisam ser aplicadas manualmente pelo operador nas máquinas de tingimento, que depois de ter passados pela balança, são encaminhados ao lado das máquinas para serem despejados nela.

A seguir, apresenta-se na Figura 8, a máquina de tingimento que faz uso desse corante que ao ser diluído em água forma uma solução ácida, podendo ser visto nitidamente o dano causado ao piso de concreto armado.

Figura 8 - Setor de Tingimento máquina

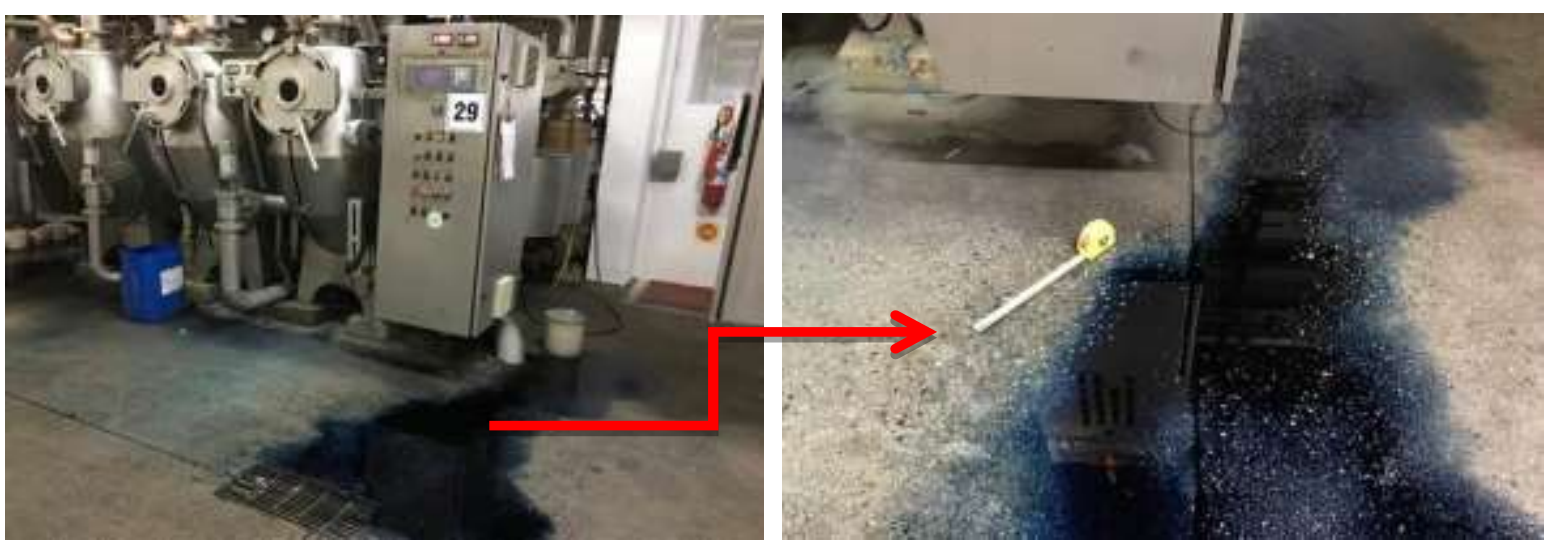

Fonte: Autores, 2017.

No setor de tingimento pode-se observar a degradação do concreto. Isso 
ocorre devido ao fato de alocar ao lado das máquinas, recipientes que contêm em seus interiores corantes que são diluídos em água formando soluções ácidas e que são despejados manualmente dentro das máquinas, neste caso, o ácido conhecido como Preto Sidercron Vsb 133\%, cujo pH varia entre 3,5-4,5 que, ao cair sobre o piso, causa tais manifestações patológicas, como se pode observar.

Como pode-se notar este corante quando diluído em água devido ao seu $\mathrm{pH}$ apresentar-se baixo forma soluções ácidas, as quais ajudam na deterioração do piso deste setor, conforme mostra a Figura 9.

Figura 9 - Setor de Tingimento

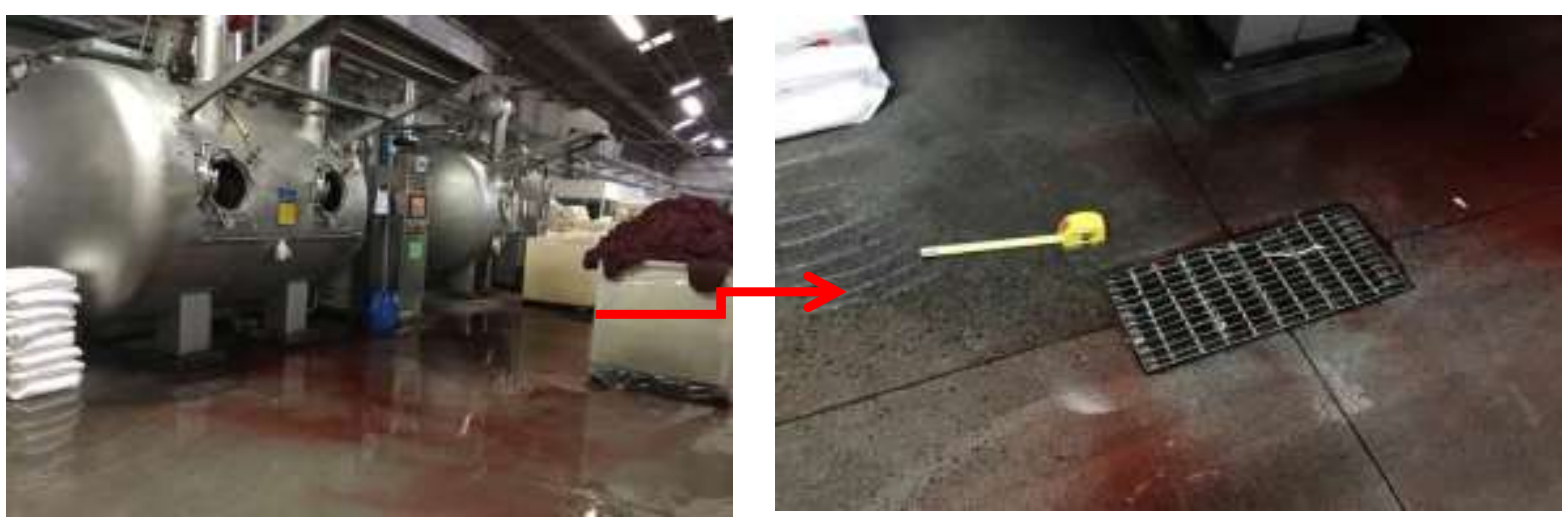

Fonte: Autores, 2017.

\section{RESULTADOS}

A tinturaria realiza o tingimento das malhas, estas precisam passar por algumas etapas e por isso necessita da separação dos setores, onde cada um deles fica responsável por realizar um procedimento, assim no Quadro 1 temos a representação de cada setor. 


\begin{tabular}{l}
\hline Quadro 1-Setores e áreas \\
\begin{tabular}{|l|l|l|l|}
\hline Setor & Área total & Área atingida \\
\hline Setor PCP & $1200 \mathrm{~m}^{2}$ & $\mathrm{X}$ \\
\hline Setor de Depósito & $1200 \mathrm{~m}^{2}$ & $\mathrm{X}$ \\
\hline $\begin{array}{l}\text { Setor de } \\
\text { Armazenamento }\end{array}$ & Produto Sólido & $200 \mathrm{~m}^{2}$ & $20 \mathrm{~m}^{2}$ \\
\cline { 2 - 4 } & Produto Líquido & $200 \mathrm{~m}^{2}$ & $12 \mathrm{~m}^{2}$ \\
\hline Setor de Tingimento & & $2000 \mathrm{~m}^{2}$ & $48 \mathrm{~m}^{2}$ \\
\hline Setor de Lavação & $300 \mathrm{~m}^{2}$ & $80 \mathrm{~m}^{2}$ \\
\hline Setor de Ramas & $2500 \mathrm{~m}^{2}$ & $30 \mathrm{~m}^{2}$ \\
\hline Setor de Calandra & $1500 \mathrm{~m}^{2}$ & $\mathrm{X}$ \\
\hline Setor de Expedição & $900 \mathrm{~m}^{2}$ & $\mathrm{X}$ \\
\hline & $10000 \mathrm{~m}^{2}$ & $190 \mathrm{~m}^{2}$ \\
\hline
\end{tabular} \\
\hline
\end{tabular}

Fonte: Autores, 2017.

A tinturaria possui uma área total de $10.000,00 \mathrm{~m}^{2}$ de piso em concreto armado, no qual sua área atingida por soluções ácidas e água apresentam aproximadamente $190 \mathrm{~m}^{2}$.

Como se pode notar, a tinturaria é dividida por 8 setores, sendo possível detectar que o setor que mais apresenta área de extensão é o de rama com 2.500 $\mathrm{m}^{2}$, seguido do menor que o de lavação com $300 \mathrm{~m}^{2}$. O Gráfico 1 demonstra as áreas da indústria, em porcentagem, cujos pisos foram degradados em seus setores.

Gráfico 1 - Porcentagem de área degradada

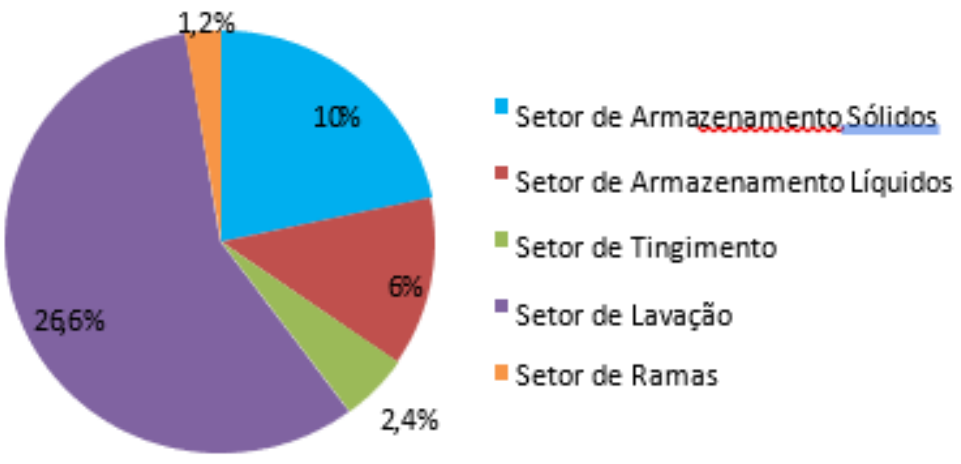

Porcentagem de área degradada

Fonte: Autores, 2017. 
São cinco os setores da tinturaria que apresentaram deterioração no seu piso. Cada um deles apresentou-se com uma determinada porcentagem de área atingida, visto que elas estão de acordo com a metragem quadrada de cada setor. Dessa forma, o setor que mais se mostrou degradado em relação aos ataques, foi o de lavação com 26,6 \% de sua área atingida, em contrapartida, o setor de ramas mostrou-se com uma menor deterioração, sendo de 1,2\%.

No Quadro 2 são apresentados os agentes agressivos ao concreto, de acordo com os registros identificados nos setores da indústria.

Quadro 2 - Agentes agressivos por setor

\begin{tabular}{|l|l|}
\hline Setor & Agentes agressivos ao concreto \\
\hline $\begin{array}{l}\text { Armazenamento de Produtos Químicos } \\
\text { (sólidos e líquidos) }\end{array}$ & Corantes, ácidos, água \\
\hline Tingimento & Corantes em soluções ácidas, água \\
\hline Lavação & Produtos ácidos (não identificados), água \\
\hline Ramas & Água \\
\hline
\end{tabular}

Fonte: Autores, 2017.

Dessa forma, no Quadro 2 pode-se notar que a presença de água está contida em todos os setores, que apresentaram o piso deteriorado. Os corantes e ácidos mostraram-se ser bastante agressivos no setor de armazenamento de produtos, uma vez que eles caem sobre o piso. Em contato com a água, quando o piso é lavado, formam rastros de degradação. No setor do tingimento, os corantes presentes em soluções ácidas, que caem dos recipientes quando lavados, depositam-se com a água e atuam de maneira significativa no piso ao lado da máquina, ajudando na degradação da capa do concreto. No setor de lavação também foram encontradas soluções ácidas, porém estas não puderam ser identificadas por motivos expressos pela empresa; contudo, verificou-se a presença de água no setor, já que o piso é diariamente lavado. No setor das ramas, o principal agente agressivo é a água, pois as caixas com malhas são depositadas nesse setor e precisam ser umedecidas por água antes de entrar para a máquina de rama.

A seguir, o Gráfico 2 traz uma representação da área dos pisos atingidos em relação à área total da indústria têxtil. 


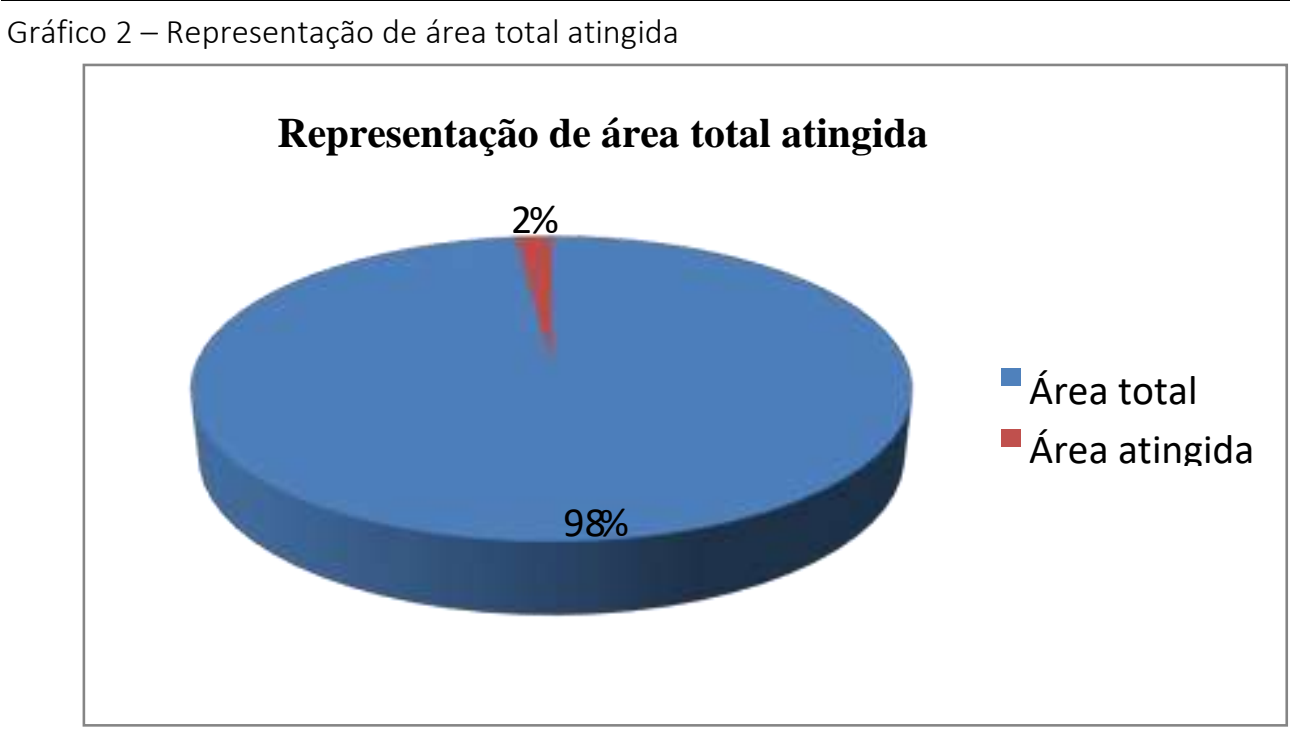

Fonte: Autores, 2017.

As patologias encontradas por meio das análises técnicas realizadas no piso industrial da tinturaria não interferem em seu desempenho. Porque como pode se observar as áreas atingidas compreendem apenas $2 \%$ da área total dos setores da indústria têxtil, ou seja, não comprometendo em nada na estrutura do piso de concreto armado.

Embora não comprometa a estrutura a mesma deve ser levada em consideração para que a corrosão não progrida ao longo do tempo.

\section{RECOMENDAÇÕES}

As patologias no piso industrial da tinturaria foram identificadas, e sugerese a manutenção preventiva, dessa forma apresenta- se dois métodos diferentes a ser aplicados; o primeiro, em fase projetual; o segundo, seu método corretivo.

O primeiro método consiste na adoção de medidas em sua fase projetual, fazendo a proteção superficial no piso de concreto armado a fim de impedir a entrada de agentes agressivos, como a água, os ácidos e as soluções ácidas, de modo a aumentar a durabilidade e evitar ou desacelerar o processo de deterioração do piso e de corrosão.

Trazendo Medeiros (2008), que corrobora que em superfícies externas de 
atmosferas industriais os sistemas compostos por primer de resina epóxi e uma demão de poliuretano disperso em solvente garantem uma proteção química ao concreto, porém são ideais para ambientes internos e atmosferas industriais, já que não possuem boa resistência à radiação ultravioleta. O mesmo autor diz ainda confirma que para se obter durabilidade de proteção é necessário ter uma boa preparação da superfície, um bom controle de qualidade na fabricação, no recebimento e na aplicação do produto.

Como as estruturas de concreto podem ser deterioradas por agentes como água, ácidos e soluções ácidas, adota-se um tratamento superficial de modo a evitar o efeito da lixiviação nos pisos industriais de concreto armado.

O segundo método consiste em recuperar os pontos degradados da estrutura de concreto armado, realizando a correção da área ou seção a ser recuperada, por duas etapas.

Dessa forma, na primeira etapa promove-se a recuperação das estruturas que precisam ser reparadas. Na segunda, encerra-se com a reconstituição das seções que foram atingidas pelo ataque de água, ácidos e soluções ácidas. A Figura 10 representa as duas etapas do método de recuperação da estrutura.

Figura 10 - Etapas da recuperação da estrutura

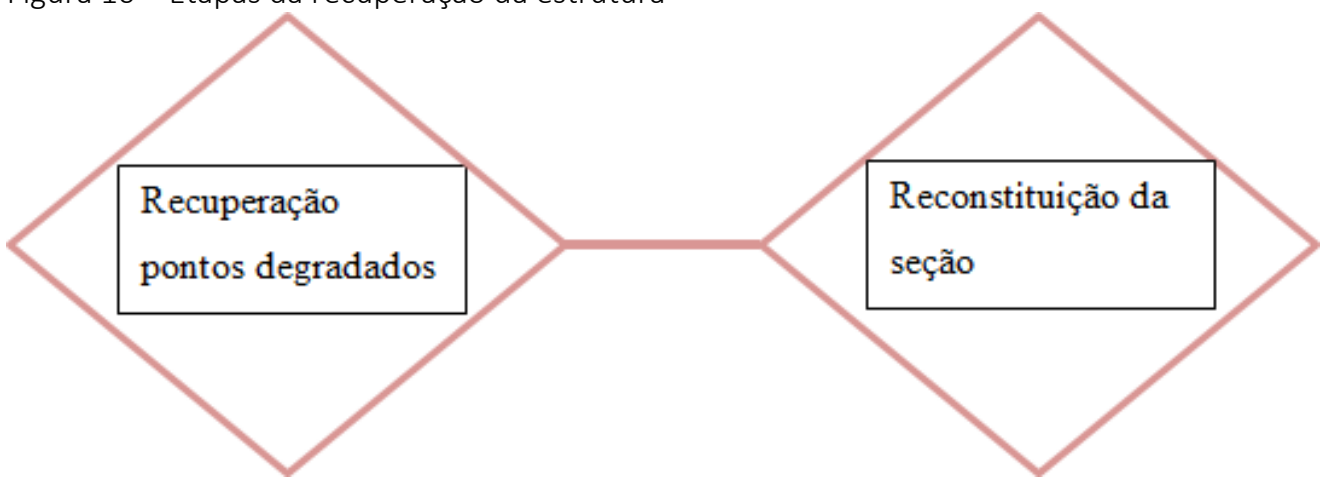

Fonte: Autores (2017)

Dessa forma, recomenda-se, devida à sua importância, a adoção por revestimentos de superfície na fase projetual e que se realizem métodos corretivos em estruturas de concreto armado quando deterioradas. 


\section{CONCLUSÕES}

O objetivo deste trabalho foi recomendar ações para mitigar ou reduzir os fenômenos patológicos oriundos de ataques ácidos em piso de uma indústria têxtil, o qual foi atingido

Referentes aos objetivos específicos, eles foram alcançados, pois o estudo do piso da tinturaria foi concluído com êxito, uma vez que os fenômenos patológicos ocasionados por água pura e por produtos químicos ácidos e soluções ácidas puderam ser estudados, além de quantificados quando encontrados.

Os fenômenos patológicos foram registrados por meio de fotos, e conforme dados fornecidos pela empresa sobre os produtos químicos, verificou-se o pH de cada produto, os quais mostraram-se com seus teores baixos e alcalinos.

Como as patologias no piso industrial da tinturaria foram identificadas, e embora com taxa de porcentagem baixa, e não apresentando risco em sua estrutura, ainda assim precisam ser reparadas, e nesse sentido sugeriu-se dois métodos de melhorias em fases distintas.

Quanto ao método de reparo, foi separado por duas fases, na projetual e no método de correção. Na fase projetual da edificação sugeriu-se a adoção de três tipos de revestimentos de proteção de superfícies para concreto armado, a fim de evitar que outras indústrias do mesmo ramo venham a sofrer com tais problemas diagnosticados neste trabalho. No método de correção sugeriu-se a recuperação do concreto.

Pôde-se observar que a deterioração do concreto ocorre onde os setores possuem um contato direto com a umidade, ou seja, nas áreas de armazenamento de produtos líquidos e sólidos, já que ele é lavado três vezes ao dia. Já no setor de tingimento onde se encontram corantes diluídos, que formam soluções ácidas por causa do seu baixo valor de $\mathrm{Ph}$, quando em contato com o concreto, ocasiona a degradação.

Da mesma forma, no setor de lavação ocorre a deterioração devido à grande quantidade de malhas que por ali percolam e, e com isso, deixam os resíduos de soluções ácidas escorrerem da malha sobre o piso, deixando-o sempre úmido, justamente pela necessidade de realizar a limpeza do local a cada turno. E no setor das ramas, pelo fato de as malhas, quando retornam do tingimento precisam ser 
molhadas para, em seguida, entrar na máquina.

Notou-se, também, que o total de área atingida por água, ácidos e corantes que formam soluções ácidas representam apenas 17\%, em contrapartida área atingida somente por água chega a 83\%, isso de acordo com as áreas de cada setor, considerando-se o total de área que a empresa possui.

Portanto, conclui-se que a área atingida do piso em concreto armado da tinturaria, mostrou-se com uma taxa baixa de porcentagem em relação à sua deterioração causada por água, ácidos e soluções ácidas e percebeu-se que a lixiviação é responsável por degradar a capa do concreto pela infiltração de soluções ácidas e de água sobre os poros do concreto, reduzindo sua resistência mecânica.

Ao finalizar este trabalho abre-se para novos estudos relacionados às patologias sobre os pisos de concreto armado de outras indústrias têxteis; a exemplo, estudar as concentrações de ácidos que mais degradam o concreto armado; analisar os tipos de revestimentos para camadas superficiais para concreto armado, pesquisar sobre os efeitos de soluções ácidas na microestrutura do concreto.

\section{REFERÊNCIAS}

ASSOCIAÇÃO BRASILEIRA DE NORMAS TÉCNICAS. NBR 14931: Execução de estruturas de concreto - procedimento. 2 ed. Rio de Janeiro:2004. 53 p. Disponível em: <https://docente.ifrn.edu.br/valtencirgomes/disciplinas/construcao-deedificios/nbr-14931-2004-execucaode-estruturas-de-concreto-procedimento>. Acesso em: 24 out. 2016.

NBR 6118: Projeto de estruturas de concreto - Procedimento. 3 ed. Rio de Janeiro: Sem, 2014. $221 \mathrm{p}$.

\section{CASCUDO, O. Inspeção e Diagnóstico de Estruturas de Concreto com Problemas de}

Corrosão da Armadura. Editor: Geraldo Cechella Isaia. São Paulo: IBRACON, 2005.

DNIT. Manual de recuperação de pontes e viadutos rodoviários. Rio de Janeiro: 2010. 161 p. Disponível em: <http://ipr.dnit.gov.br/normasemanuais/manuais/documentos/744_manual_recuperacao_pontes_viadutos.pdf>. Acesso em: 11 out. 2016.

FERREIRA, Rui Miguel. Avaliação dos ensaios de durabilidade do betão. 2000. 246 f. 
Dissertação (Mestrado em Engenharia Civil) - Escola de Engenharia, Universidade do Minho, Braga, 2000.

HELENE, Paulo R. L. Envelhecimento e Inserção de pontes e viadutos. São Paulo: 1998. $21 \mathrm{p}$.

MARCELLI, Maurício. Sinistros na construção civil: Causas e soluções para danos e prejuízos em obras. São Paulo: Pini, 2007. 259 p.

RAUPP, Fabiano Maury; BEUREN, Ilse Maria. Metodologia da pesquisa aplicável às ciências sociais. 2. ed. São Paulo: Atlas, 2004.

SILVA, Marise Borba da; SCHAPPO, Vera Lúcia. Introdução à pesquisa em educação. Florianópolis, UDESC, 2002.

SOUZA, Vicente Custódio Moreira de; RIPPER, Thomaz. Patologia, recuperação e reforço de estruturas de concreto. São Paulo: Pini, 1998. 253 p.

TRIVIÑOS, A. N. S. Introdução à pesquisa em ciências sociais: a pesquisa qualitativa em educação. São Paulo, Atlas, 1987. 